\title{
Prediction of portal and hepatic blood flow from intake level data in cattle
}

\author{
J. L. Ellis, ${ }^{*} \dagger^{1}$ C. K. Reynolds, $\ddagger$ L. A. Crompton, $\ddagger$ M. D. Hanigan,§ A. Bannink,\# J. France, † and J. Dijkstra* \\ *Animal Nutrition Group, Wageningen University, Wageningen, 6708 WD, the Netherlands \\ †Centre for Nutrition Modeling, Department of Animal Biosciences, University of Guelph, Guelph, ON, N1G 2W1, Canada \\ ¥School of Agriculture, Policy and Development, University of Reading, PO Box 237, Earley Gate, Reading, RG6 6AR, Berkshire, UK \\ $\S$ College of Agriculture and Life Science, Virginia Tech University, 175 West Campus Drive, Blacksburg 24061 \\ \#Animal Nutrition, Wageningen UR Livestock Research, Wageningen, 6708 WD, the Netherlands
}

\begin{abstract}
Interest is growing in developing integrated postabsorptive metabolism models for dairy cattle. An integral part of linking a multi-organ postabsorptive model is the prediction of nutrient fluxes between organs, and thus blood flow. The purpose of this paper was to use a multivariate meta-analysis approach to model portal blood flow (PORBF) and hepatic venous blood flow (HEPBF) simultaneously, with evaluation of hepatic arterial blood flow (ARTBF; ARTBF $=\mathrm{HEPBF}-\mathrm{PORBF})$ and PORBF $/ \mathrm{HEPBF}(\%)$ as calculated values. The database used to develop equations consisted of 296 individual animal observations (lactating and dry dairy cows and beef cattle) and 55 treatments from 17 studies, and a separate evaluation database consisted of 34 treatment means (lactating dairy cows and beef cattle) from 9 studies obtained from the literature. Both databases had information on dry matter intake (DMI), metabolizable energy intake (MEI), body weight, and a basic description of the diet including crude protein intake and forage proportion of the diet (FP; \%). Blood flow (L/h or $\mathrm{L} / \mathrm{kg}$ of $\mathrm{BW}^{0.75} / \mathrm{h}$ ) and either DMI or MEI ( $\mathrm{g}$ or $\mathrm{MJ} / \mathrm{d}$ or $\mathrm{g}$ or $\mathrm{MJ} / \mathrm{kg}$ of $\mathrm{BW}^{0.75} / \mathrm{d}$ ) were examined with linear and quadratic fits. Equations were developed using cow within experiment and experiment as random effects, and blood flow location as a repeated effect. Upon evaluation with the evaluation database, equations based on DMI typically resulted in lower root mean square prediction errors, expressed as a \% of the observed mean (rMSPE\%) and higher concordance correlation coefficient (CCC) values than equations based on MEI. Quadratic equation terms were frequently nonsignificant, and the quadratic equations did not outperform their linear counterparts. The best performing blood flow equations were PORBF $(\mathrm{L} / \mathrm{h})=202( \pm 45.6)+83.6( \pm 3.11) \times$ DMI $(\mathrm{kg} / \mathrm{d})$
\end{abstract}

Received September 11, 2015.

Accepted July 22, 2016.

${ }^{1}$ Corresponding author: jen.ellis.stpierre@gmail.com and HEPBF $(\mathrm{L} / \mathrm{h})=186( \pm 45.4)+103.8( \pm 3.10) \times$ DMI $(\mathrm{kg} / \mathrm{d})$, with rMSPE\% values of 17.5 and 16.6 and CCC values of 0.93 and 0.94 , respectively. The residuals (predicted - observed) for PORBF/HEPBF were significantly related to the forage $\%$ of the diet, and thus equations for PORBF and HEPBF based on forage and concentrate DMI were developed: $\operatorname{PORBF}(\mathrm{L} / \mathrm{h})=$ $210( \pm 51.0)+82.9( \pm 6.43) \times$ forage $(\mathrm{kg}$ of $\mathrm{DM} / \mathrm{d})+$ $82.9( \pm 6.04) \times$ concentrate $(\mathrm{kg}$ of $\mathrm{DM} / \mathrm{d})$, and HEPBF $(\mathrm{L} / \mathrm{h})=184( \pm 50.6)+92.6( \pm 6.28) \times$ forage $(\mathrm{kg}$ of $\mathrm{DM} / \mathrm{d})+114.2( \pm 5.88) \times$ concentrate $(\mathrm{kg}$ of $\mathrm{DM} / \mathrm{d})$, where $\mathrm{rMSPE} \%$ values were 17.5 and 17.6 and CCC values were 0.93 and 0.94 , respectively. Division of DMI into forage and concentrate fractions improved the joint Bayesian information criterion value for PORBF and HEPBF (Bayesian information criterion $=6,512$ vs. 7,303$)$, as well as slightly improved the rMSPE and CCC for ARTBF and PORBF/HEPBF. This was despite minimal changes in PORBF and HEPBF predictions. Developed equations predicted blood flow well and can easily be used within a postabsorptive model of nutrient metabolism. Results also suggest different sensitivity of PORBF and HEPBF to the composition of DMI, and accounting for this difference resulted in improved ARTBF predictions.

Key words: blood flow, portal, hepatic, cattle, metaanalysis, multivariate

\section{INTRODUCTION}

The ability of current feed ration systems to predict the effects of MP supply on milk protein production and nitrogen excretion to the environment by dairy cattle is limited by an oversimplified representation of postabsorptive metabolism (Lapierre et al., 2006). Given the variability in postabsorptive metabolism, there is interest in developing integrated postabsorptive models of metabolism (portal-drained viscera, liver, mammary gland, and other organs or tissues) to replace current empirical feeding systems for cattle. Integration of such organ-based models requires prediction of nutrient flow between organs, including prediction of hepatic arterial 
(ARTBF), portal venous (PORBF) and hepatic venous (HEPBF) blood flows (BF). Across the liver, the relative contribution of ARTBF and PORBF can have a significant effect on nutrient fluxes through the organ (e.g., Barnes et al., 1986), warranting reliable prediction of these BF. Nutrient concentration in PORBF is modified by the net absorption of nutrients following digestion of feeds (or the net utilization of nutrients from arterial blood), whereas ARTBF nutrient concentration is mainly the result of the residual balance between nutrient absorption, utilization, endogenous synthesis, and mobilization from body tissues. Several attempts to model ARTBF, PORBF, and HEPBF in ruminants are present in the literature, but (1) were conducted on sheep (e.g., Vernet et al., 2009), (2) use older metaanalysis techniques that exclude random effects (e.g., Lescoat et al., 1996), or (3) examined only 1 of the 3 BF of interest (e.g., Huntington, 1984; Bermingham et al., 2008). Species differences in BF (e.g., between cattle and sheep) have already been observed (Vernet et al., 2005; Bermingham et al., 2008), indicating that cross-species application of BF equations may be inappropriate. Equations developed using older metaanalysis techniques may inherently contain prediction errors (St-Pierre, 2001; Sauvant et al., 2008). A fully integrated postabsorptive model for cattle would require all $3 \mathrm{BF}$ to be estimated simultaneously. Therefore, a multivariate meta-analysis approach, simultaneously fitting equations for ARTBF, PORBF, and HEPBF, while accounting for the interrelationship between $\mathrm{BF}$, is warranted.

The purpose of this study was therefore (1) to investigate the simultaneous prediction of ARTBF, HEPBF, and PORBF for cattle via a multivariate meta-analysis on published studies, considering DMI and metabolizable energy intake (MEI) as driving variables, and (2) to compare these predictions to available extant prediction equations on an evaluation database in order to identify the most appropriate prediction equations for use in future cattle metabolism models.

\section{MATERIALS AND METHODS}

\section{Developmental Database}

The database used for equation development is summarized in Table 1. It consisted of 17 studies with 296 individual animal means and 55 treatment means. Published experiments included Reynolds et al. (1991, 1992a,b, 1993, 1994a,b, 1995a,b, 1998, 1999, 2001, 2003a,b), Caton et al. (2001), Hanigan et al. (2004), Maltby et al. (2005), and Røjen et al. (2011). Experiments covered both lactating and dry dairy cows and growing beef cattle (steers and heifers). Method of BF measurement was downstream dilution of para-aminohippuric acid (Katz and Bergman, 1969) for all studies. Within studies, BF results were means of (between) 5 to 12 hourly measurements. All reported BF values are on a whole-blood basis. Criteria for inclusion in the developmental database included availability of individual animal data and provision of information on both PORBF and HEPBF, DMI, MEI, BW, and forage $\%(\mathbf{F P})$ in the diet. Within study, any treatments that were not nutritional were removed to minimize nonnutritional variation in the database.

Within the database, the average SD within treatment across the database (indicator of within treatment animal variability) was $135 \mathrm{~L} / \mathrm{h}, 210 \mathrm{~L} / \mathrm{h}, 177 \mathrm{~L} / \mathrm{h}$, and $0.852 \mathrm{~kg} / \mathrm{d}$ for ARTBF, PORBF, HEPBF, and DMI, respectively, and the average $\mathrm{SD}$ of treatment means (indicator of variation across treatment means) was 152 $\mathrm{L} / \mathrm{h}, 548 \mathrm{~L} / \mathrm{h}, 673 \mathrm{~L} / \mathrm{h}$, and $6.35 \mathrm{~kg} / \mathrm{d}$ for ARTBF, PORBF, HEPBF, and DMI, respectively. Preliminary analysis (not shown) revealed that within-treatment BF variation was significantly related to within-treatment DMI variation $(P<0.01)$.

\section{Evaluation Database}

The database used for equation evaluation is summarized in Table 2. It consisted of 9 studies with 34 treatment means extracted from the published literature (Wieghart et al., 1986; Eisemann and Nienaber, 1990; Huntington et al., 1990; Guerino et al., 1991; Reynolds and Tyrrell, 1991; Casse et al., 1994; Eisemann and Huntington, 1994; Whitt et al., 1996; Alio et al., 2000) and included both lactating dairy cows and beef cattle. Method of BF measurement for all studies was downstream dilution of para-aminohippuric acid (Katz and Bergman, 1969). Similar to the developmental database, all reported $\mathrm{BF}$ values are for whole blood. Criteria for inclusion in the database included published studies with provision of information on PORBF, HEPBF, DMI, MEI, BW, and FP. Having MEI and simultaneous reporting of PORBF and HEPBF as inclusion criteria for the evaluation database limited the number of potential studies that could be included, but ensured an equal comparison between DMI and MEI, and PORBF and HEPBF based equations. Similar to the developmental database, within study, any treatments that were not nutritional were removed to minimize nonnutritional variation in the database.

The observed PORBF and HEPBF versus DMI relationship for both the developmental and evaluation databases are presented in Figure 1 and the distribution of FP across DMI in Figure 2. 
Table 1. Summary of the blood flow (hepatic arterial $=$ ARTBF; portal venous $=$ PORBF; hepatic venous $=$ HEPBF) developmental database ${ }^{1}$

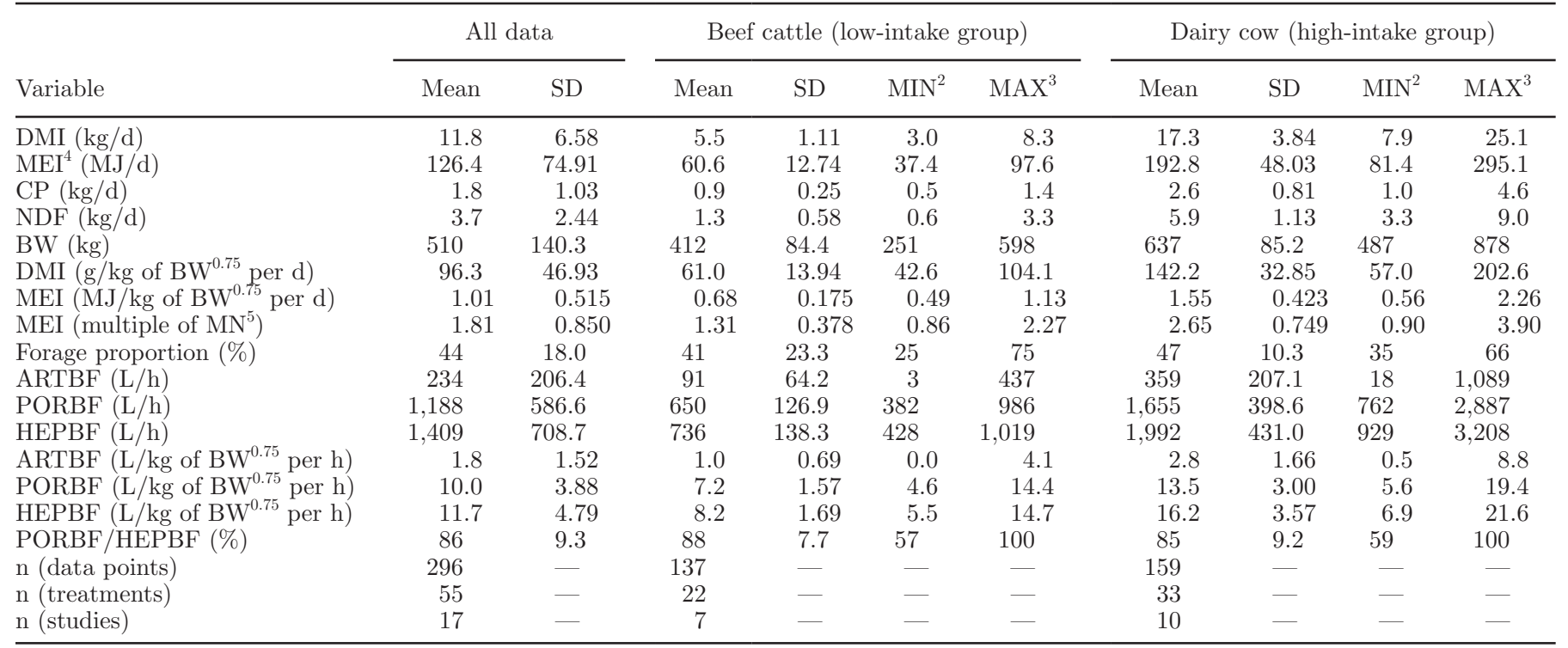

${ }^{1}$ Mean and SD reported are based on $\mathrm{n}$ (data points).

${ }^{2}$ Minimum value in database.

${ }^{3}$ Maximum value in database.

${ }^{4} \mathrm{MEI}=\mathrm{ME}$ intake.

${ }^{5} \mathrm{MN}=$ maintenance energy requirement.

\section{Equation Development}

To model the effect of DMI and MEI of cattle on ARTBF, PORBF and HEPBF, mixed model analysis was performed. Linear and quadratic multivariate mixed model analysis was conducted using the NLINMIX macro of SAS (NLMM 8.0 SAS, SAS Institute Inc., Cary, NC; Moser, 2004; Littell et al., 2006), with simultaneous parameterization of the response variables (PORBF, HEPBF) and representation of the

Table 2. Summary of the blood flow (hepatic arterial = ARTBF; portal venous $=$ PORBF; hepatic venous $=$ HEPBF) evaluation database ${ }^{1}$

\begin{tabular}{|c|c|c|c|c|}
\hline Variable & Mean & $\mathrm{SD}$ & $\mathrm{MIN}^{2}$ & $\mathrm{MAX}^{3}$ \\
\hline DMI (kg/d) & 8.4 & 4.71 & 4.3 & 21.8 \\
\hline $\mathrm{MEI}^{4}(\mathrm{MJ} / \mathrm{d})$ & 90.4 & 43.59 & 51.1 & 231.5 \\
\hline $\mathrm{CP}(\mathrm{kg} / \mathrm{d})$ & 1.3 & 0.89 & 0.7 & 4.0 \\
\hline BW (kg) & 387 & 97.5 & 198 & 538 \\
\hline DMI $\left(\mathrm{g} / \mathrm{kg}\right.$ of $\mathrm{BW}^{0.75}$ per $\left.\mathrm{d}\right)$ & 94.0 & 36.91 & 57.1 & 204.6 \\
\hline MEI (MJ/kg of BW ${ }^{0.75}$ per d) & 1.02 & 0.346 & 0.62 & 2.17 \\
\hline MEI (multiple of $\mathrm{MN}^{5}$ ) & 1.99 & 0.613 & 1.16 & 3.94 \\
\hline Forage proportion (\%) & 42 & 22.0 & 10 & 100 \\
\hline $\operatorname{ARTBF}(\mathrm{L} / \mathrm{h})$ & 165 & 137.9 & 26 & 563 \\
\hline PORBF (L/h) & 832 & 369.3 & 336 & 1,992 \\
\hline $\operatorname{HEPBF}(\mathrm{L} / \mathrm{h})$ & 996 & 495.9 & 400 & 2,524 \\
\hline $\operatorname{ARTBF}\left(\mathrm{L} / \mathrm{kg}\right.$ of $\mathrm{BW}^{0.75}$ per $\left.\mathrm{h}\right)$ & 1.8 & 1.24 & 0.3 & 5.3 \\
\hline PORBF (L/kg of BW $\mathrm{BW}^{0.75}$ per $\left.\mathrm{h}\right)$ & 9.4 & 2.95 & 6.4 & 18.7 \\
\hline $\mathrm{HEPBF}\left(\mathrm{L} / \mathrm{kg}\right.$ of $\mathrm{BW}^{0.75}$ per $\left.\mathrm{h}\right)$ & 11.2 & 3.96 & 7.5 & 23.7 \\
\hline PORBF/HEPBF (\%) & 85 & 5.9 & 76 & 97 \\
\hline n (data points) & 34 & & & \\
\hline $\mathrm{n}$ (treatments) & 34 & & & \\
\hline n (studies) & 9 & & & \\
\hline
\end{tabular}

${ }^{1}$ Mean and SD reported are based on $\mathrm{n}$ (data points).

${ }^{2}$ Minimum value in database.

${ }^{3}$ Maximum value in database.

${ }^{4} \mathrm{MEI}=\mathrm{ME}$ intake.

${ }^{5} \mathrm{MN}=$ maintenance energy requirement. 

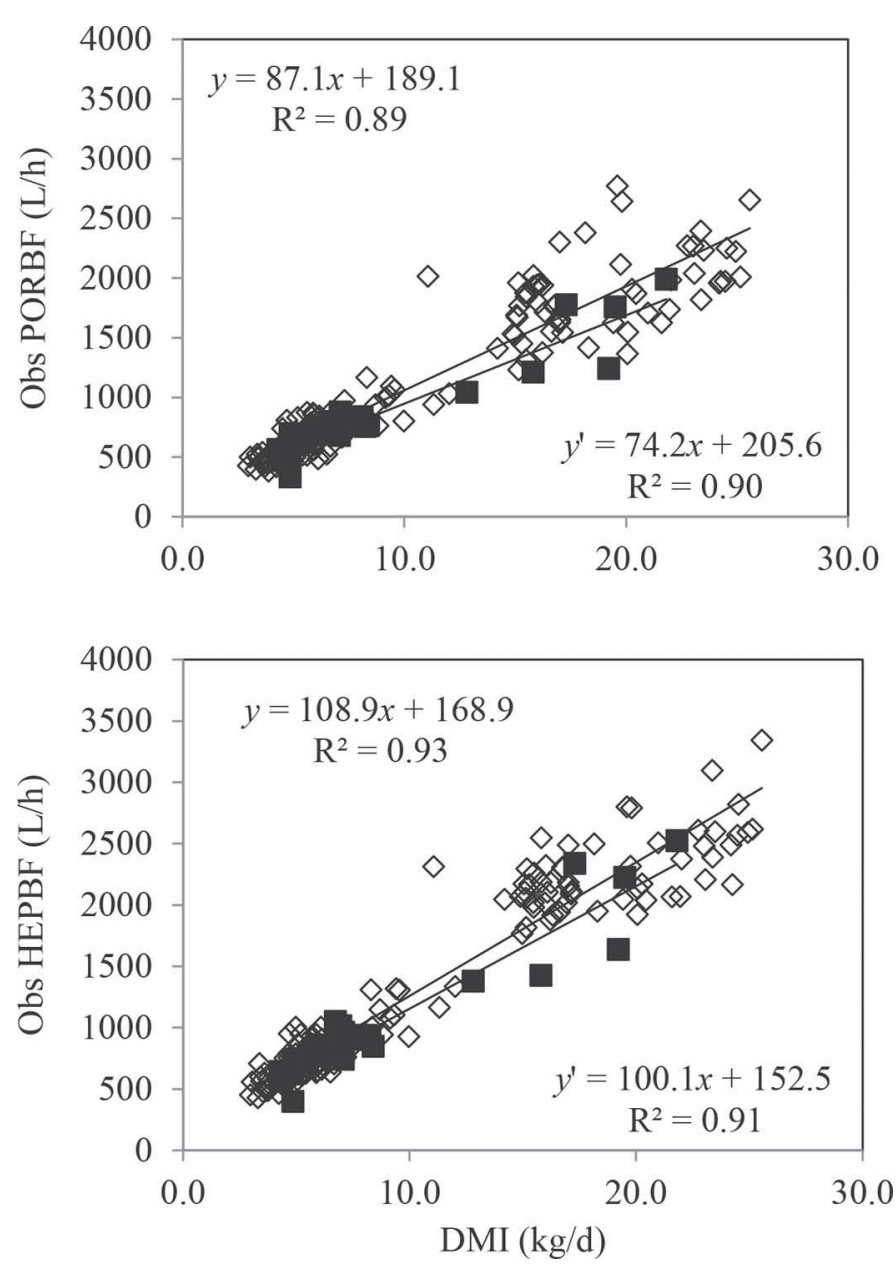

Figure 1. Observed portal blood flow (PORBF, L/d; top) and hepatic blood flow (HEPBF, L/d; bottom) versus DMI $(\mathrm{kg} / \mathrm{d}$ ) for the developmental database $(\diamond, y)$ and the evaluation database $\left(\boldsymbol{\square}, y^{\prime}\right)$.

correlation between these variables via the repeated effects statement (Strathe et al., 2010a). For a recent example of NLMM code, see the appendix of Strathe et al. (2010b).

Due to the high degree of error and low sensitivity of ARTBF to the driving variables, it was difficult to obtain convergence of the multivariate model when ART$\mathrm{BF}$ was modeled directly (not shown). This is likely because ARTBF is a comparatively small flow determined by difference experimentally (in vivo, observed ARTBF = observed HEPBF - observed PORBF). As a result, predicted ARTBF was determined by calculation of the difference between predicted PORBF and HEPBF. Similarly, PORBF/HEPBF (\%) was evaluated as the ratio of predicted $\mathrm{BF}$, and not modeled directly.

As the data were compiled from multiple studies, it was necessary to analyze not only the fixed effects of the dependent variables, but also the random effect of experiment as this accounts for differences be-

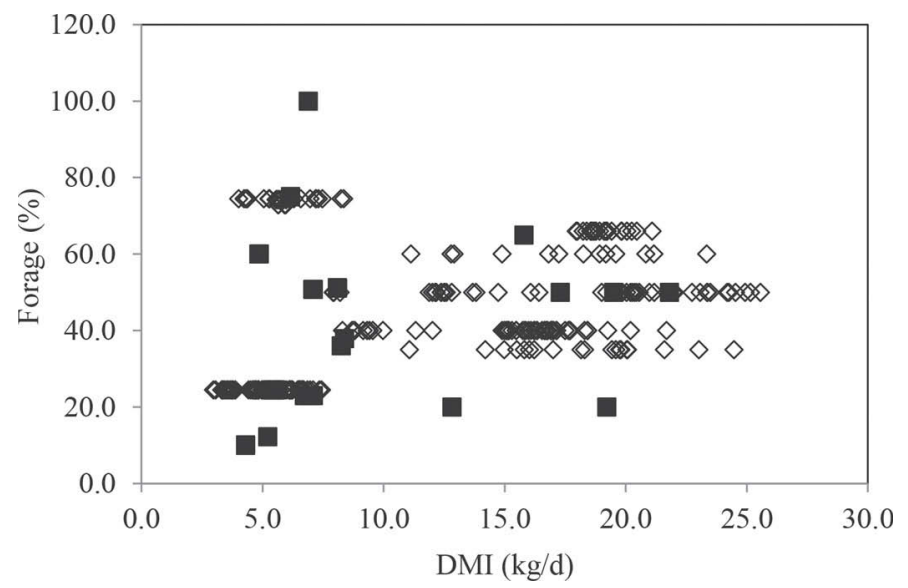

Figure 2. Distribution of forage $\%$ across DMI $(\mathrm{kg} / \mathrm{d})$ for the developmental $(\diamond)$ and evaluation ( $\mathbf{\square})$ databases.

tween experiments such as physiological status of the animals, experimental design, measurement methods, techniques, and laboratory variation (St-Pierre, 2001; Sauvant et al., 2008). As it was desirable to examine the between animal variation in DMI and BW, the full model also included the random effect of cow nested within experiment.

The statistical model can be written as follows, where fixed and random effects are incorporated directly into parameters:

$$
\begin{gathered}
Y_{i j k}=f\left(\varnothing_{i j}, \text { intake }_{i j k}\right)+e_{i j k} . \\
\emptyset_{i j}=\left[\begin{array}{c}
\emptyset_{1 i j} \\
\emptyset_{2 i j} \\
\cdot \\
\cdot \\
\emptyset_{d i j}
\end{array}\right]=\left[\begin{array}{c}
B_{11} \cdot x_{1}+B_{12} \cdot x_{2} \\
B_{21} \cdot x_{1}+B_{22} \cdot x_{2} \\
\cdot \\
\cdot \\
B_{d 1} \cdot x_{1}+B_{d 2} \cdot x_{2}
\end{array}\right]+\left[\begin{array}{c}
b_{i}^{(1)} \\
b_{i}^{(2)} \\
\cdot \\
\cdot \\
b_{i}^{(d)}
\end{array}\right]+\left[\begin{array}{c}
b_{i, j}^{(1)} \\
b_{i, j}^{(2)} \\
\cdot \\
\cdot \\
b_{i, j}^{(d)}
\end{array}\right] .
\end{gathered}
$$

The function $f$ is a linear or quadratic function of intake (DMI or MEI), with the parameter vector $\varnothing_{i j}$ and model error $e_{i j k}$. The experiment and cow(experiment) random effects, $\left\{b_{i}\right\}$ and $\left\{b_{i, j}\right\}$, are assumed independent of each other and independent of within cow errors $e_{i j k}$. The $B$ 's are the fixed effects influencing the curve parameters due to BF (PORBF, HEPBF), and are introduced via 2 dummy variables $x_{1}$ and $x_{2}$, respectively.

Initial analysis revealed a potential fan shape in the residuals, where residual variance increased with the predicted $\mathrm{BF}$ value. In addition, within-treatment and across-treatment $\mathrm{BF}$ variation increased as $\mathrm{BF}$ or DMI (or both) increased $(P<0.05$; data not shown). This may reflect the different type of animals used at low 
and high DMI (beef cattle vs. dairy cows), milk yield or body reserve mobilization, or the range of diets examined. To compensate, a variance weighting statement (wt) was added to the NLMM macro model, wt $=1$ / (predicted value) $^{2}$, which decreased variance weight with increasing predicted BF value (see Strathe et al., 2010b for discussion).

The joint distribution of random effects was assumed to be multivariate normal and the dual quasi-Newton technique was used for optimization with an adaptive Gaussian quadrature as the integration method.

\section{Equation Evaluation}

Goodness of fit of the statistical model (inclusion/ exclusion of random effects, variance/covariance structure selection, and so on) was evaluated using the Bayesian information criterion (BIC) fit statistic (SAS Inst. Inc.), where lower values indicate better model fit, and the value and significance of the fixed effect model parameters were tested against a $P$-value of 0.05 .

Evaluation of newly developed and extant equations against the evaluation database were performed via 2 methods. First, root mean square prediction error (rMSPE) was performed, where the mean square prediction error (MSPE) is calculated as

$$
\operatorname{MSPE}=\sum_{i=1}^{n}\left(O_{i}-P_{i}\right)^{2} / n,
$$

where $n$ is the total number of observations, $O_{i}$ is the observed value, and $P_{i}$ is the predicted value. The rMSPE, expressed as a percentage of the observed mean, gives an estimate of the overall prediction error. The rMSPE can also be decomposed into error in central tendency or mean bias, error due to deviation of the regression slope from unity, and error due to the disturbance (random error; Bibby and Toutenburg, 1977).

Second, concordance correlation coefficient analysis (CCC) was performed (Lin, 1989), where CCC is calculated as

$$
\mathrm{CCC}=r \times C_{b},
$$

where $r$ is the Pearson correlation coefficient and $C_{b}$ is a bias correction factor. The $r$ variable gives a measure of precision, whereas $C_{b}$ is a measure of accuracy. Associated CCC variables (used in calculation of $C_{b}$ ) are $v$, which provides a measure of scale shift, and $u$, which provides a measure of location shift relative to the scale. The $v$ value indicates the change in standard deviation, if any, between predicted and observed val- ues. A $v$ value greater than 1.0 indicates larger variance in the predicted data compared with observed, whereas a $v$ value less than 1.0 indicates a smaller variance in the predicted data compared with observed. A positive $u$ value indicates overprediction, whereas a negative $u$ value indicates underprediction.

\section{RESULTS AND DISCUSSION}

\section{Low vs. High Intake}

Visual inspection of the data revealed 2 potential clusters within the databases, representing a cluster of lower-intake and higher-intake data (Figure 1). These intake groups are confounded with animal type, and also represent clusters of studies, where the low intake group comprised all beef cattle data and the high intake group comprised all dairy cow data. As a result, analysis was initially performed by separating the data (by studies) into low and high intake groups (or, alternatively, animal type; Table 1), and analyzing for statistical differences between intake-group parameter estimates. In sheep, Vernet et al. $(2005,2009)$ suggested that $\mathrm{BF}$ responses to DMI or MEI differed based on the level of intake. Additionally, physiological status may have an effect on BF. A major difference between the data of Vernet et al. $(2005,2009)$ and the current data (aside from species) is, however, that in the current developmental database level of intake did not fall far below maintenance requirements (Table 1). In this study, the average multiple of maintenance feeding level was $1.31( \pm 0.378)$ for the low-intake and $2.65( \pm 0.749)$ for the high-intake groups, compared with 0.5 and 1.3 in the study of Vernet et al. (2009), respectively. Separation of studies into 2 intake groups in the current data set did not result in significantly different parameter estimates between low- and high-intake groups $(P>$ 0.09; Table 3). As a result, separate equations for the low intake and high intake groups (or animal type) are not reported, and equations reported were fit to the full database.

\section{Linear and Quadratic Blood Flow Equations}

Results of linear and quadratic curve fitting to the BF developmental database are presented in Table 3. Equations were fit to data with BF units of liters per hour combined with DMI or MEI units of kilograms per day or megajoules per day, or with $\mathrm{BF}$ units of liters per kilogram of $\mathrm{BW}^{0.75} /$ hour combined with DMI or MEI units of grams per kilogram of $\mathrm{BW}^{0.75}$ / day or megajoules per kilogram of $\mathrm{BW}^{0.75} /$ day. Scaling relative to $\mathrm{BW}$ was also examined, but resulted in no improvements over $\mathrm{BW}^{0.75}$, and is not reported. 


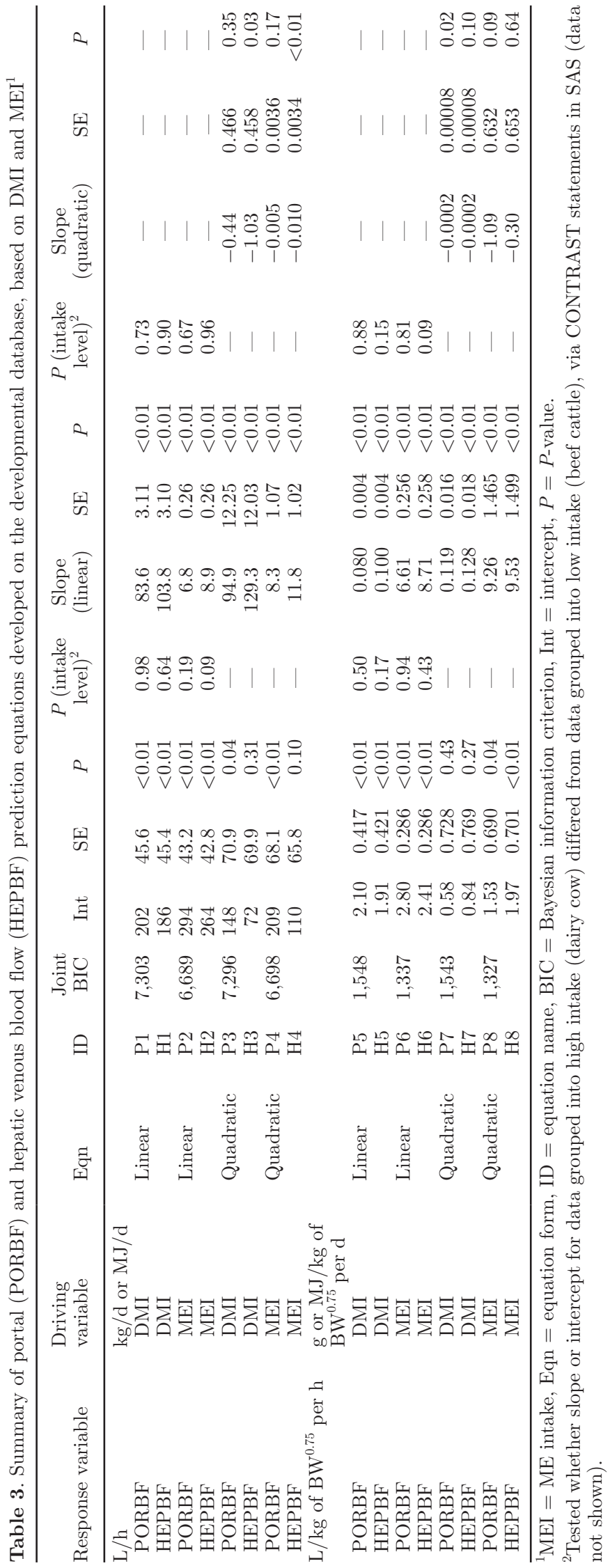

Model structure (random effects, variance-covariance structures, variance weighting) was optimized to ensure convergence and to minimize the joint $\mathrm{BIC}$ value. Joint BIC values represent the BIC for PORBF and HEPBF combined, which were fit simultaneously. The significance of parameter estimates (vs. zero) are reported, as well as the $P$-value for testing the low versus high intake parameter estimates against each other, via CONTRAST statements in SAS (Table 3). This division into low and high intake groups was not performed for quadratic equations due mainly to lack of convergence, but also because a quadratic fit should inherently capture changes in the slope of the relationship across intake level. In support of the findings that parameter estimates did not differ significantly between low and high intake groups, fitting quadratic equations to the developmental database resulted in similar or marginally better joint BIC values, and the quadratic parameter estimates were not always significant (Table $3)$. Lack of significance of the quadratic parameter indicates potential overparametrization of the model or that the relationship was linear within the range of data available. When BF was expressed in units of liters per hour, the negative quadratic parameter was significant for HEPBF, but not for PORBF (driving variable of DMI or MEI). When BF was expressed in units of liters per kilogram of $\mathrm{BW}^{0.75}$ /hour, the quadratic parameter was only significant for PORBF with DMI as a driving variable. Linear equation parameters (slope and intercept) were always significant $(P<0.01)$.

Equations based on MEI had lower BIC values compared with equations based on DMI (Table 3), indicating better model fit. Conclusions on $\mathrm{BF}$ units cannot be made based on BIC, as BIC values are scaled by the units.

\section{DMI and MEI Based Equation Evaluation}

Equations developed were tested on an independent evaluation database (described in Table 2) to compare prediction precision and accuracy. Although the evaluation database may be considered somewhat small relative to the size of the developmental database, it does represent a complete data set, where all variables predicted and evaluated were reported in the publications. Results are presented in Table 4 for PORBF, HEPBF, ARTBF (predicted by difference), and PORBF/HEP$\mathrm{BF}(\%$, ratio of predicted $\mathrm{BF})$ for each equation.

Comparing DMI to MEI as the driving variable, DMI typically resulted in slightly better predictions based on rMSPE and CCC results, except for PORBF/HEPBF (Table 4). This could be the result of added variation or error due to MEI determination. However, Han et al. (2002) also suggested that portal BF responded primar- 
ELLIS ET AL.

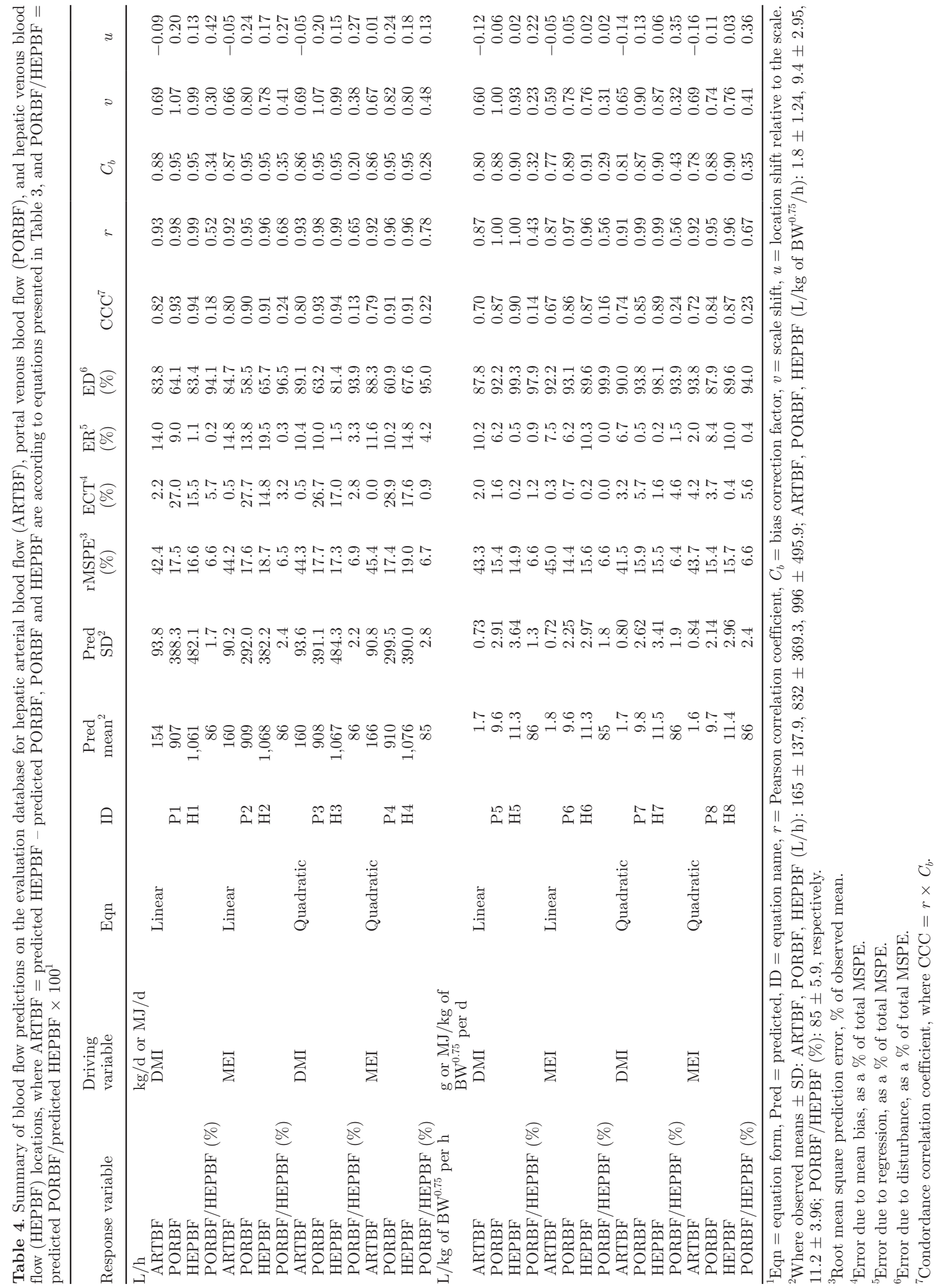


ily to bulk fill rather than nutrient supply. Reynolds et al. (1991) suggested that in addition to ME consumed, ME density of the diet affected PORBF and HEPBF via effects of forage content on gut fill and subsequent effects on gut mass and the work of digestion, which may also explain the better relationship for splanchnic BF and DMI. Vernet et al. (2009) found a similar lack of improvement with MEI over DMI in predicting BF in sheep. Therefore, it is likely that this observation has a physiological basis rather than being error related.

Comparing linear to quadratic equations, predictions were similar but slightly improved with the linear equations (Table 4). As many of the quadratic parameter estimates were not significant, this is not a surprising result.

Comparing liters per hour and liters per kilogram of $\mathrm{BW}^{0.75} / \mathrm{h}$ as units for $\mathrm{BF}, \mathrm{CCC}$ results were in general slightly improved when liters per hour was used and rMSPE results were in general slightly improved when liters per kilogram of $\mathrm{BW}^{0.75} /$ hour was used (Table 4). Scaling with $\mathrm{BW}^{0.75}$ reduced the contribution of nonrandom error sources (error in central tendency or mean bias, and error due to deviation of the regression slope from unity) to the rMSPE total, indicating improved predictions compared with scaling without $\mathrm{BW}^{0.75}$. However for $\mathrm{CCC}, \mathrm{BW}^{0.75}$ scaling reduced the total CCC via a decrease in $C_{b}$, despite a slight increase in $r$. This difference in results is likely due to differences in division of error within rMSPE and CCC calculations (for a discussion see Ellis et al., 2010). Scaling by $\mathrm{BW}^{0.75}$ is presumed to extend the range of data the equations may be applicable to, and thus was of interest when combining dairy and beef data, but it may also introduce additional variation due to BW measurement (difficulty getting a precise scale number, variation in gut fill contribution to BW, and so on). For whichever reason, these results indicate that scaling by $\mathrm{BW}^{0.75}$ may not improve predictions of BF over units of liters per hour, as performance between the equations was similar.

Predictions for PORBF and HEPBF, as evaluated by rMSPE and CCC analysis, were typically very good, with CCC values greater than 0.84 and $\mathrm{rMSPE}$ values less than 19\% (Table 4). The best predictions of PORBF and $\mathrm{HEPBF}$ when $\mathrm{BF}$ was expressed in liters per hour were the linear equations with DMI as the driving variable (P1 and $\mathrm{H} 1$ equations; rMSPE $=17.5$ and $16.6 \%$, $\mathrm{CCC}=0.93$ and 0.94 , respectively). Similarly, when PORBF and HEPBF were expressed relative to $\mathrm{BW}^{0.75}$, the linear DMI equations resulted in slightly better predictions (P5 and $\mathrm{H} 5$ equations; $\mathrm{rMSPE}=15.4$ and $14.9 \%, \mathrm{CCC}=0.87$ and 0.90 , respectively). However, in general predictions were similar and good across all equations with only minor differences.
Residual analysis was conducted on the seemingly best performing equations (linear, DMI; L/h and L/kg of $\mathrm{BW}^{0.75} / \mathrm{h}$ ), and is displayed in Figure 3. Residuals plotted against predicted BF (Figure 3) did not reveal any significant trends in the data $(P>0.05)$, nor for the most part when plotted against the driving variable DMI $\left(\mathrm{kg} / \mathrm{d}\right.$ or $\mathrm{g} / \mathrm{kg}$ of $\left.\mathrm{BW}^{0.75} / \mathrm{d} ; P>0.05\right)$, with the exception of residual ARTBF $(\mathrm{L} / \mathrm{h})$, where $P=0.04$ [residual ARTBF $(\mathrm{L} / \mathrm{h})=40.2( \pm 29.2)-6.4( \pm 2.83) \times$ $\mathrm{DMI}(\mathrm{kg} / \mathrm{d})$; graphs not shown]. The residuals were also plotted against the forage proportion (FP, \%) of the diet, and although the regression was not significant for ARTBF, PORBF, or $\operatorname{HEPBF}(P>0.05)$, it was significant for PORBF/HEPBF $(\% ; P=0.03$ and 0.03 , for $\mathrm{L} / \mathrm{h}$ and $\mathrm{L} / \mathrm{kg}$ of $\mathrm{BW}^{0.75} / \mathrm{h}$ equations, respectively; Figure 4). As the result of the FP pattern in the residuals, the FP of the diet was considered as an additional driving variable. The results of separating forage and concentrate DMI is outlined in the following section.

\section{Separating Forage and Concentrate DMI}

To further examine the potential effect of the FP of the diet, DMI was separated into forage and (starch-rich) concentrate components $(\mathrm{kg} / \mathrm{d})$ in the developmental database, and new equations were parameterized for PORBF and HEPBF, with ARTBF again calculated by difference. Equations developed are presented in Table 5.

When testing the PORBF forage and concentrate slopes against each other, the difference between parameter estimates was nonsignificant (Table 5), indicating no difference in effect of type of DMI on PORBF. However, testing HEPBF forage and concentrate slope parameters against each other revealed a significant difference, the slope for concentrate being higher (Table $5)$. This result suggests a higher sensitivity of HEPBF to FP or energy intake compared with PORBF. In support of this, the slope of MEI-based equations was also generally higher for HEPBF than for PORBF (Table $3)$. This may reflect an increased absorption and liver metabolism of propionate and other VFA with an increasing concentrate proportion in diet DM (Huntington, 1990).

Dividing DMI into forage and concentrate components resulted in improved joint BIC values (Table 3 vs. Table 5), slightly improved ARTBF and PORBF/ HEPBF predictions, and similar PORBF and HEPBF predictions compared with equations based on total DMI (Table 4 vs. Table 6).

Interpretation of these FP equations is challenging. For PORBF, it appears forage and concentrate DMI do not differ in their magnitude of effect on BF (similar parameter estimates). This may, however, be the com- 
(a)

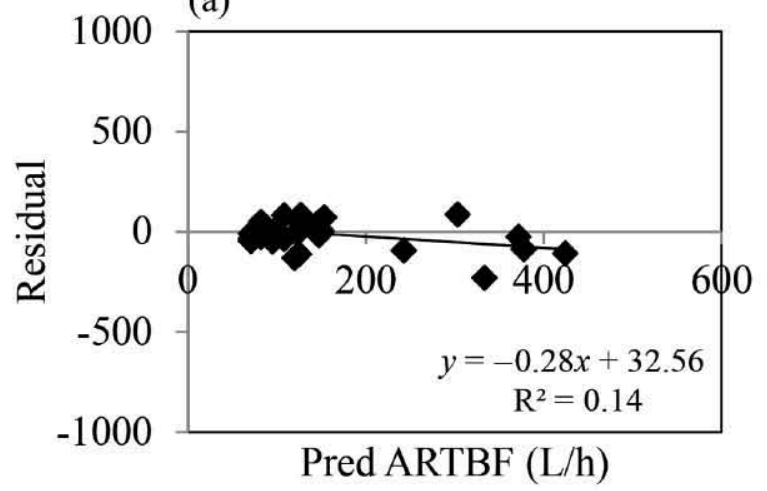

(b)

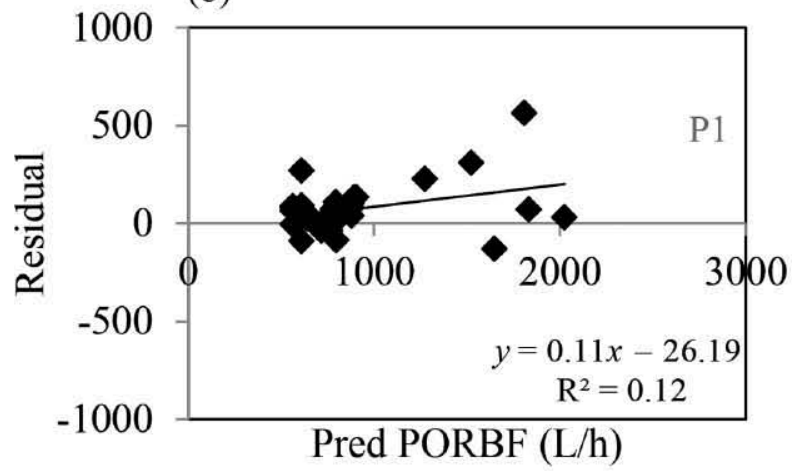

(c)

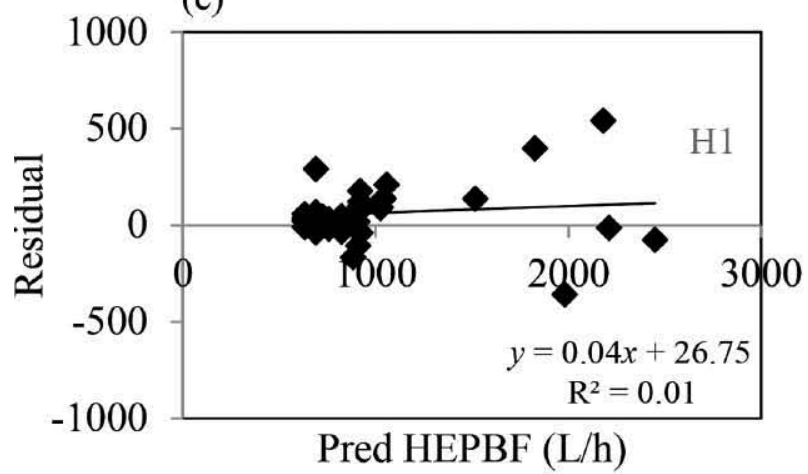

(d)

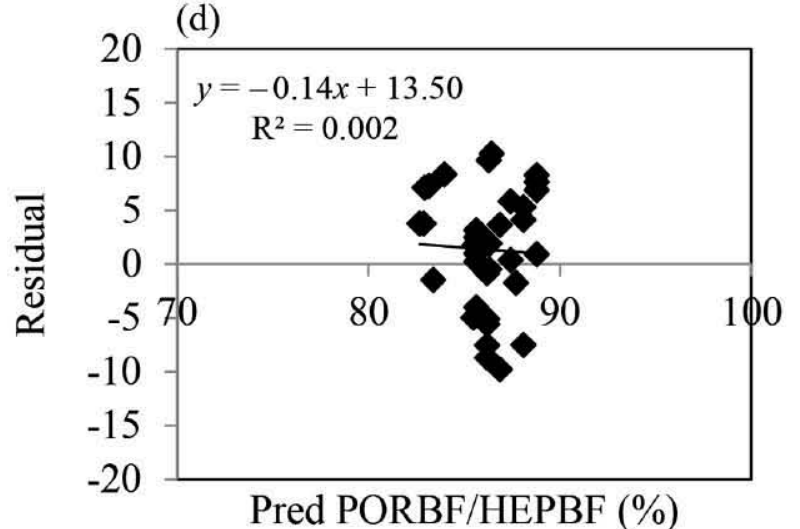

(a)

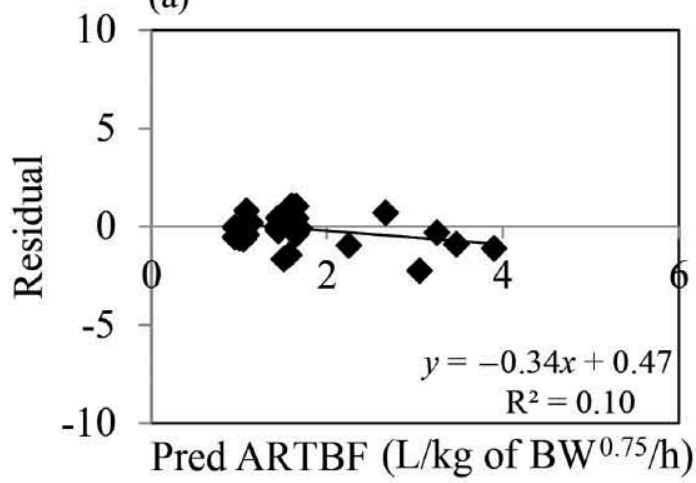

(b)

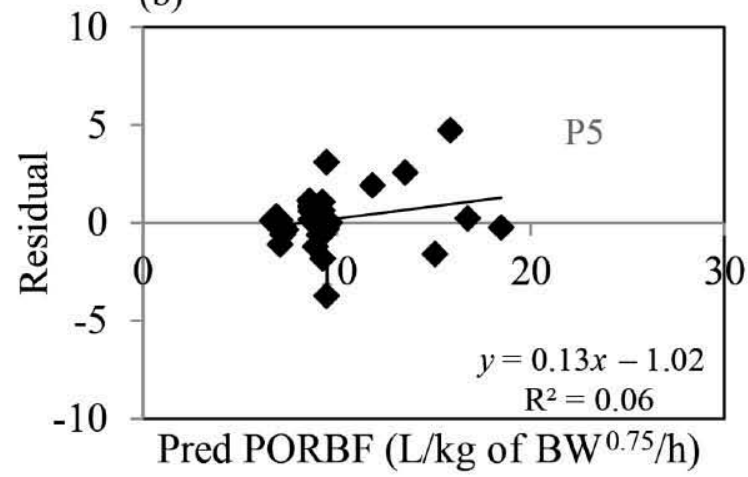

(c)

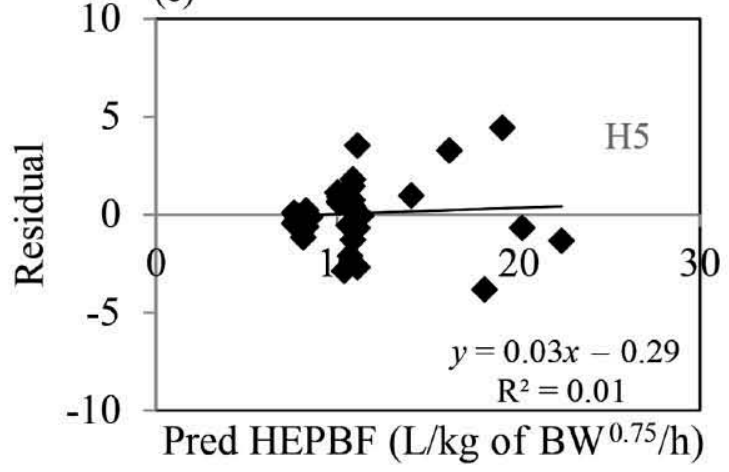

(d)

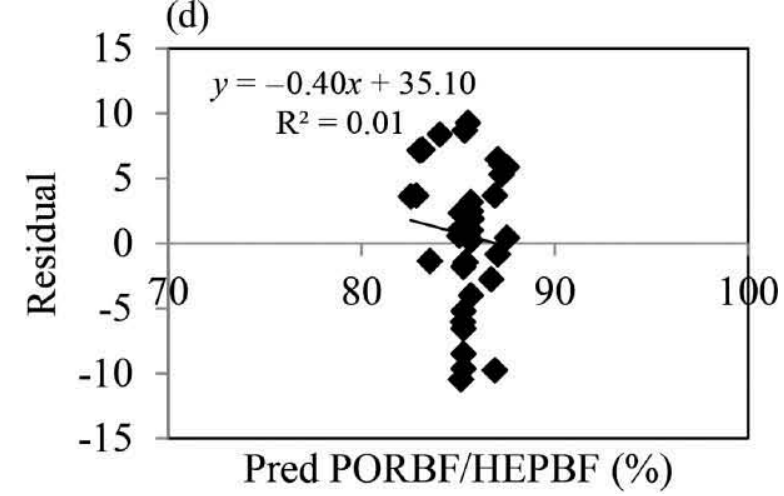

Figure 3. Residual (predicted - observed value) versus predicted blood flow values for the linear DMI-based equations (Table 3) based on blood flow in liters per hour (left) or liters per kilogram of $\mathrm{BW}^{0.75}$ hour (right), evaluated on the evaluation database for hepatic arterial blood flow (ARTBF; a), portal venous blood flow (PORBF; b), hepatic venous blood flow (HEPBF; c), and PORBF/HEPBF \% (d). 
(a)

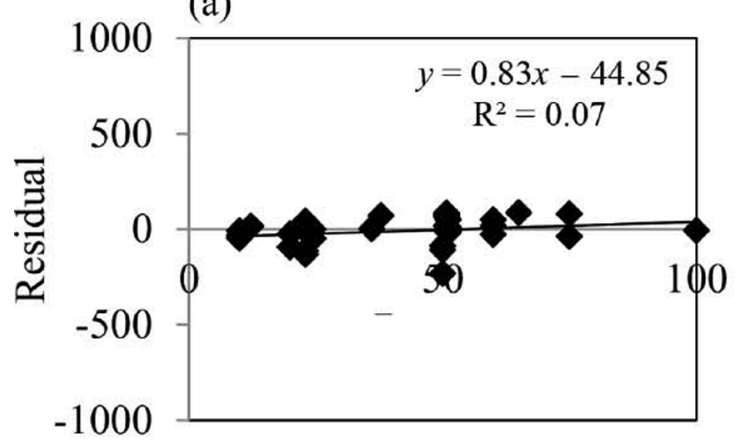

(b)

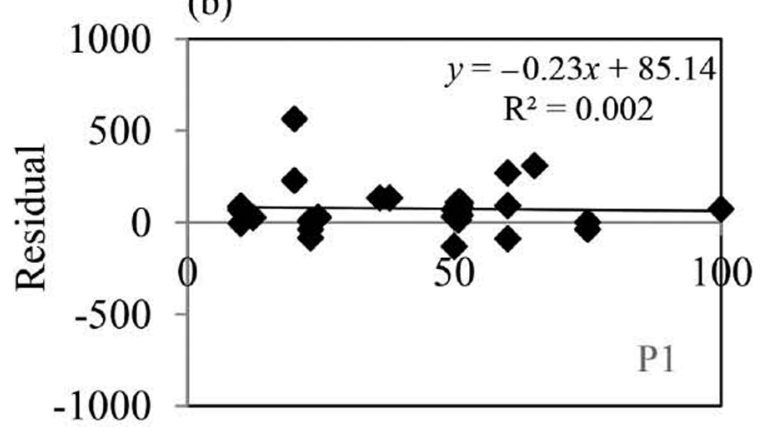

(c)

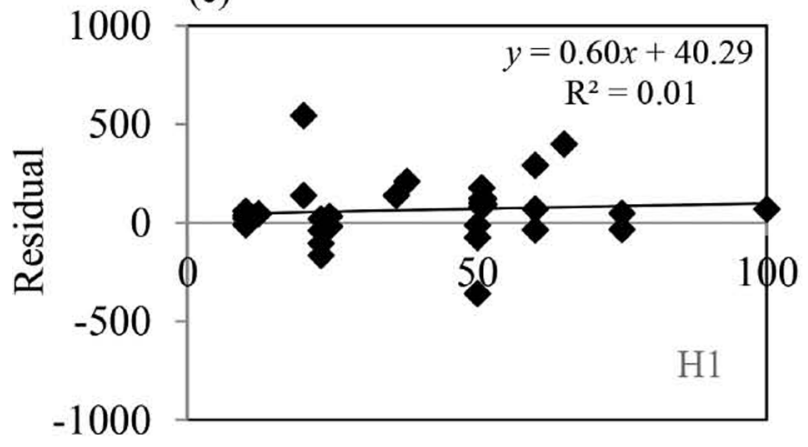

(d)

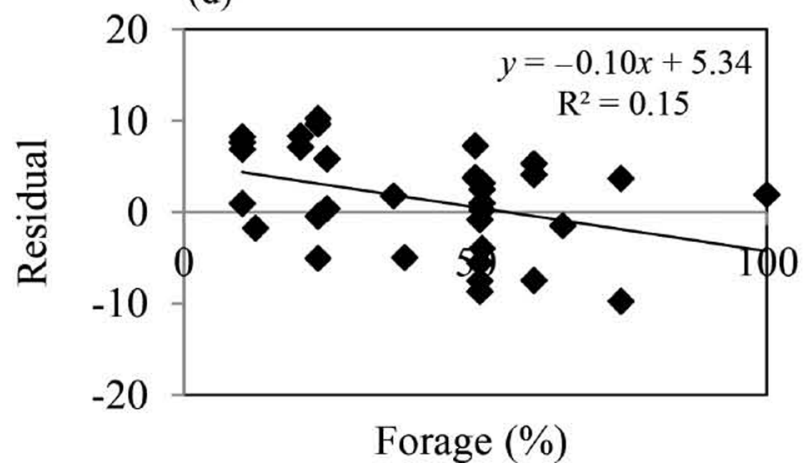

(a)

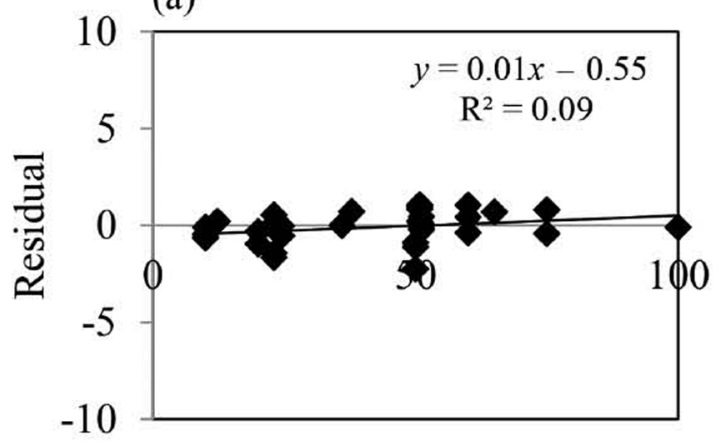

(b)

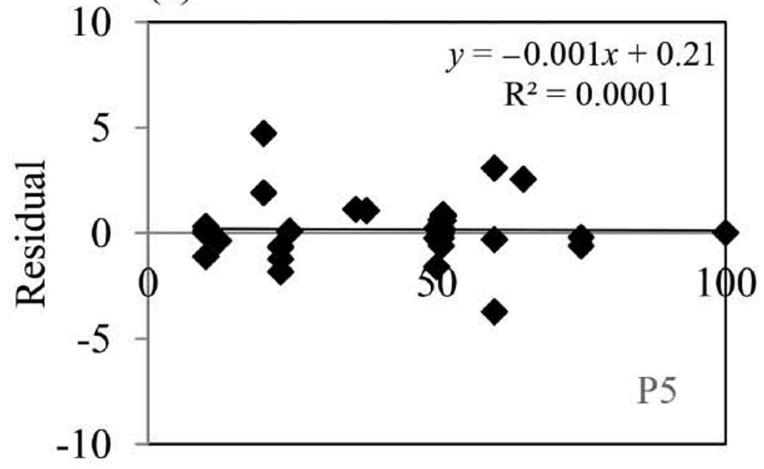

(c)

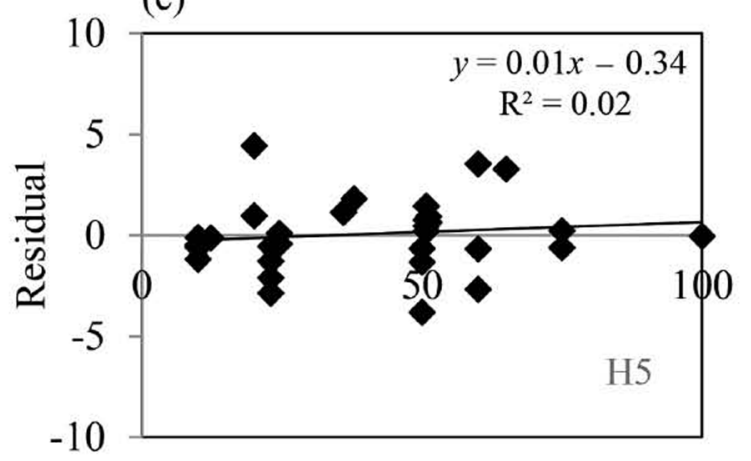

(d)

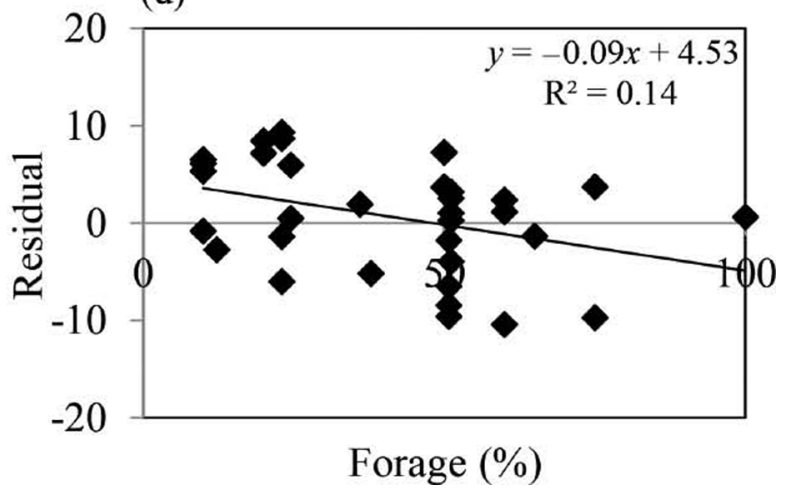

Figure 4. Residual (predicted - observed value) versus the forage proportion (\%) of the diet for the DMI-based equations (Table 3) based on blood flow in liters per hour (left) or liters per kilogram of $\mathrm{BW}^{0.75}$ hour (right), evaluated on the evaluation database for hepatic arterial blood flow (ARTBF; a), portal venous blood flow (PORBF; b), hepatic venous blood flow (HEPBF; c), and PORBF/HEPBF (d). 
pound result of 2 opposing mechanisms: forage DMI may stimulate BF less than concentrate DMI due to lower energy content and digestibility, but this may be countered by a higher bulk fill value that is stimulatory to BF (Reynolds et al., 1991).

In contrast, it appears that HEPBF may be more sensitive to concentrate (or energy intake) than to forage intake (significantly different parameter estimates), suggesting that total liver $\mathrm{BF}$ is still more heavily regulated by energy status and absorption of VFA and other components of ME than gut fill. Vernet et al. (2009) made similar observations in sheep.

Although these differences did not greatly alter PORBF and HEPBF predictions, predictions of the calculated ARTBF and PORBF/HEPBF were both improved. This suggests that whereas DMI alone may predict PORBF or HEPBF adequately, differences between them (ARTBF) may be better predicted with consideration of the diet FP. Vernet et al. (2009) did not examine residuals of arterial/venous $\mathrm{BF}$ against FP, but they did observe a significant relationship between the residuals and OM digestibility, suggesting again that $\mathrm{BF}$ depends on both bulk and the nutrient density of the diet. To better understand these effects, an examination of the regulation of liver BF is required.

\section{Blood Flow Regulation Through Splanchnic Tissues}

Blood flow through the portal vein, the main blood supply to the liver, is regulated by the portal-drained viscera, which is responsible for nutrient uptake and delivery to the postabsorptive environment, as opposed to being controlled by the liver (Lautt, 2009). Bulk fill as well as nutrient delivery to the animal affects this flow (e.g., Reynolds et al., 1991) through regulation by intrinsic and extrinsic mechanisms. Intrinsic mechanisms include local metabolic control (response to oxygen supply and demand), myogenic control (transmural pressure), local reflexes (presence of lumen contents), and locally produced vasoactive substances (e.g., gastrin, secretin, cholecystokinin; Lautt, 1996, 2009). The extrinsic factors include sympathetic innervation, circulating vasoactive substances and systemic hemodynamic changes (Lautt, 1996, 2009). Hepatic arterial blood flow, while regulated by local tissue oxidation levels in other organs, is also not regulated by the liver (Lobley et al., 2000). Instead, it appears that ARTBF regulation is linked to PORBF, ensuring the liver receives a constant total $\mathrm{BF}$ relative to liver mass (Lautt, 1996, 2009). This appears to be regulated via a continuous release of adenosine into the space of Mall, independent of oxygen supply or demand, followed by removal through both ARTBF and PORBF. Adenosine itself is a powerful vasodilator (Lautt, 2009). If PORBF 


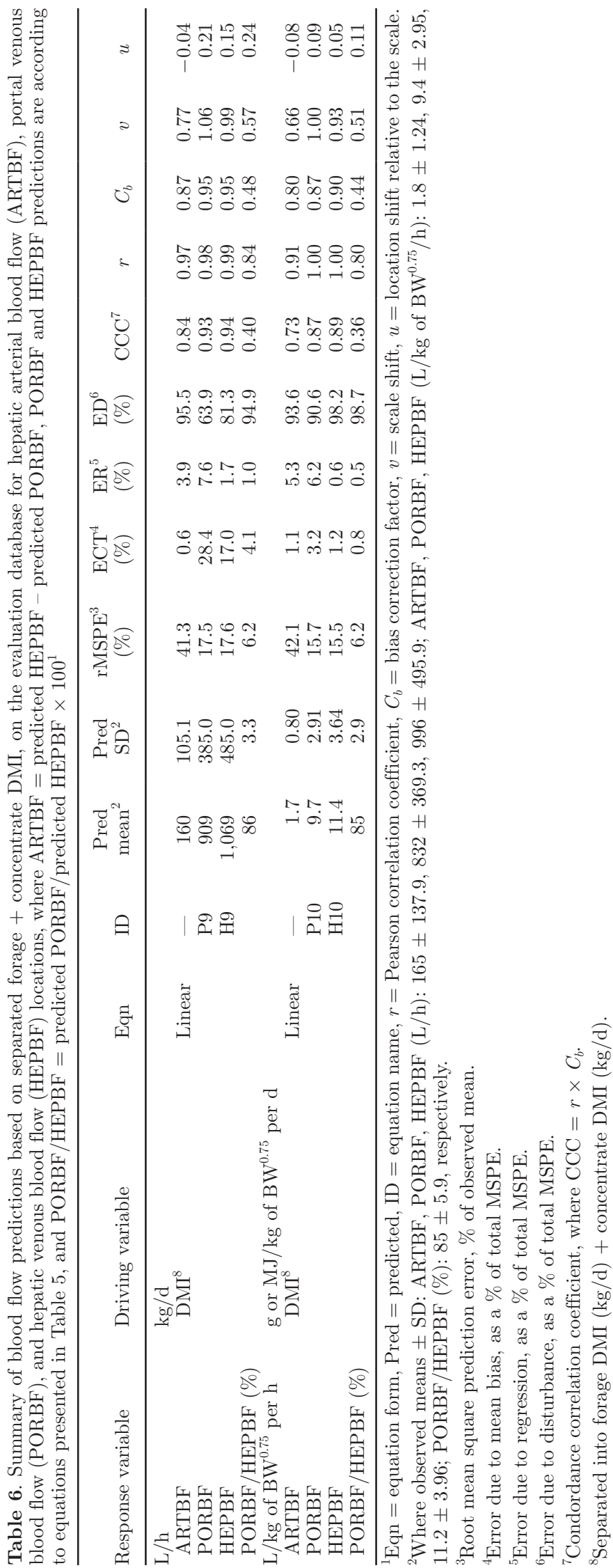


is reduced, the local concentration of adenosine increases, stimulating arterial vasodilation and increasing ARTBF to remove the adenosine. On the other hand, when PORBF is high (e.g., during peak absorption of nutrients from the rumen), this may cause a reduction in ARTBF due to a decrease in local adenosine concentrations. This process is referred to as the hepatic arterial buffer response. In this respect, the liver does not drive either of the incoming BF; PORBF is driven by the portal-drained viscera, and ARTBF is driven, inversely, by PORBF. However, the liver can have significant indirect regulatory effects on incoming $\mathrm{BF}$, via mechanisms affecting $B F$ to splanchnic organs that drain into the PORBF. As well, longer term effects on $\mathrm{BF}$ can be mediated by changes in liver mass. For a full review of liver BF regulation, see Lautt (2009).

Based on the empirical $\mathrm{BF}$ prediction equations developed in the present work, it is possible that stimulation of PORBF by concentrate (energy) intake is countered by a depression in PORBF by a lower forage intake (bulk fill), resulting in similar forage and concentrate parameters for PORBF prediction across a range of $\mathrm{FP}$. When $\mathrm{FP}$ was low and total DMI alone was the driving variable, PORBF/HEPBF was overpredicted $(P<0.05)$ and as a result ARTBF slightly underpredicted (nonsignificant; Figure 4). This makes sense as ARTBF is calculated as HEPBF - PORBF. At a low FP, overprediction of PORBF/HEPBF could be due to overprediction of PORBF or underprediction of HEPBF (or both). Examination of the (albeit nonsignificant) slope terms in Figure 4 suggests that both are occurring to some extent.

As parameterization with separate forage and concentrate DMI resulted in similar parameters for PORBF, if these results reflect in vivo observations, it suggests that for low FP diets HEPBF is underrepresented by using total DMI because of an underrepresented ARTBF contribution. This suggests that while total $\mathrm{BF}$ through the liver is sensitive to energy intake (and thus different forage and concentrate parameters for HEPBF), factors reducing PORBF relative to the local adenosine concentration (in this case, FP or bulk fill) may drive an increase in ARTBF to compensate. Thus, separating forage and concentrate DMI captures this effect of ARTBF, without directly modeling ARTBF.

When interpreting these results, it should be noted that whereas DMI varied within all studies, FP did not. Although the equations were parameterized on kilograms per day of forage and concentrate, in the developmental database 5 of 17 studies specifically examined FP effects, and 4 of 9 studies in the evaluation database examined FP effects. The distribution of FP across DMI is illustrated in Figure 2. Therefore, the forage + concentrate equations require examination on an additional database with additional variation in $\mathrm{FP}$ to ensure it is not just an artifact of the data used.

\section{Equations Based on Diet Chemical Composition}

Although one of the main purposes of this paper was to compare DMI and MEI as the major drivers of PORBF and HEPBF in a multivariate analysis, CP and NDF content of the diet were also available in the developmental database. Therefore, initially, development of equations based on CP or NDF intake $(\mathrm{kg} / \mathrm{d}$ or $\mathrm{g} / \mathrm{kg}$ of $\mathrm{BW}^{0.75} / \mathrm{d}$ ) were also considered. However, while these equations had BIC values comparable to the forage + concentrate DMI equations [joint BIC values were 6,413 for $\mathrm{CP}(\mathrm{kg} / \mathrm{d}), 6,534$ for $\mathrm{NDF}(\mathrm{kg} / \mathrm{d}), 1,391$ for $\mathrm{CP}\left(\mathrm{g} / \mathrm{kg}\right.$ of $\left.\mathrm{BW}^{0.75} / \mathrm{d}\right)$, and 1,491 for NDF $(\mathrm{g} / \mathrm{kg}$ of $\mathrm{BW}^{0.75} / \mathrm{d}$ ) based equations], their rMSPE and CCC values were worse than those of DMI and MEI le.g., CP $(\mathrm{kg} / \mathrm{d})$ predicting PORBF $(\mathrm{L} / \mathrm{h})$ resulted in $\mathrm{rMSPE} \%$ $=37.8, \mathrm{CCC}=0.63$ and $\mathrm{HEPBF}(\mathrm{L} / \mathrm{h}) \mathrm{rMSPE} \%=$ 37.9 and $\mathrm{CCC}=0.69$, on the evaluation database]. As a result, these equations were not pursued further. However, equations developed considering multiple chemical components of the diet might be considered in the future, in particular given the relationship observed here with FP.

\section{Comparison with Extant Blood Flow Equations}

To compare predictions of the newly developed $\mathrm{BF}$ equations to extant equations, several equations were selected from the literature and applied to the evaluation database. The equations of Lescoat et al. (1996) were not included, as the evaluation database used here shared data with the developmental database used by Lescoat et al. (1996), resulting in unsurprisingly good $\mathrm{BF}$ predictions by these equations (not shown). Although the equations of Vernet et al. (2009) were developed for sheep, it represented an interesting challenge to include their equations for comparison on cattle data.

Extant equation evaluations are presented in Table 7. Of the equations evaluated, the PORBF equation of Huntington (1984) based on MEI performed comparably to the newly developed PORBF equations in terms of rMSPE and CCC analysis. These equations (Huntington, 1984) were developed on beef and dairy heifer data. The linear PORBF equation of Bermingham et al. (2008) performed adequately, with slightly more bias (overprediction) and lower CCC values. However, similar to the results found in the current study, the quadratic equation for PORBF by Bermingham et al. (2008) did not improve predictions over their linear equation. These equations were developed on a combination of sheep and cattle data. 
PREDICTION OF LIVER BLOOD FLOW IN CATTLE

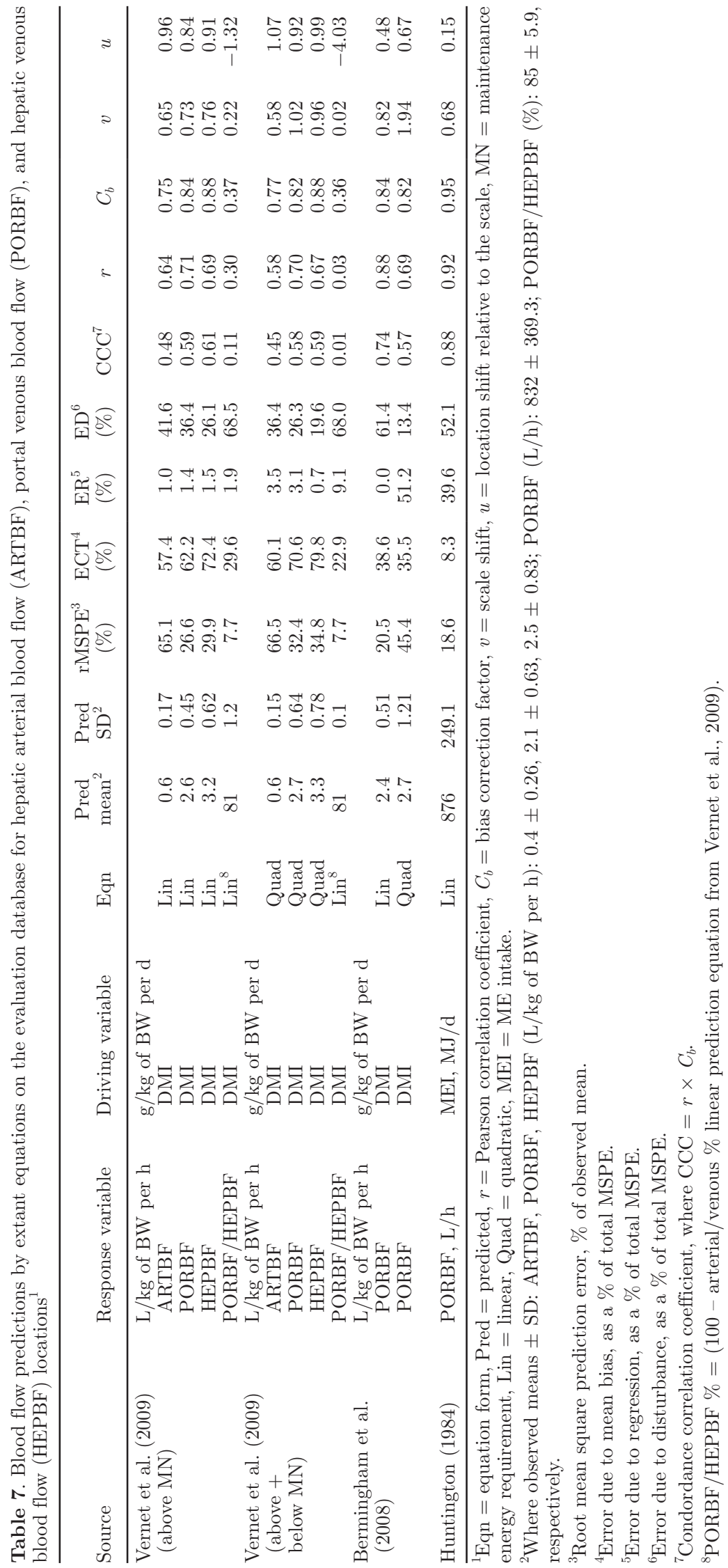



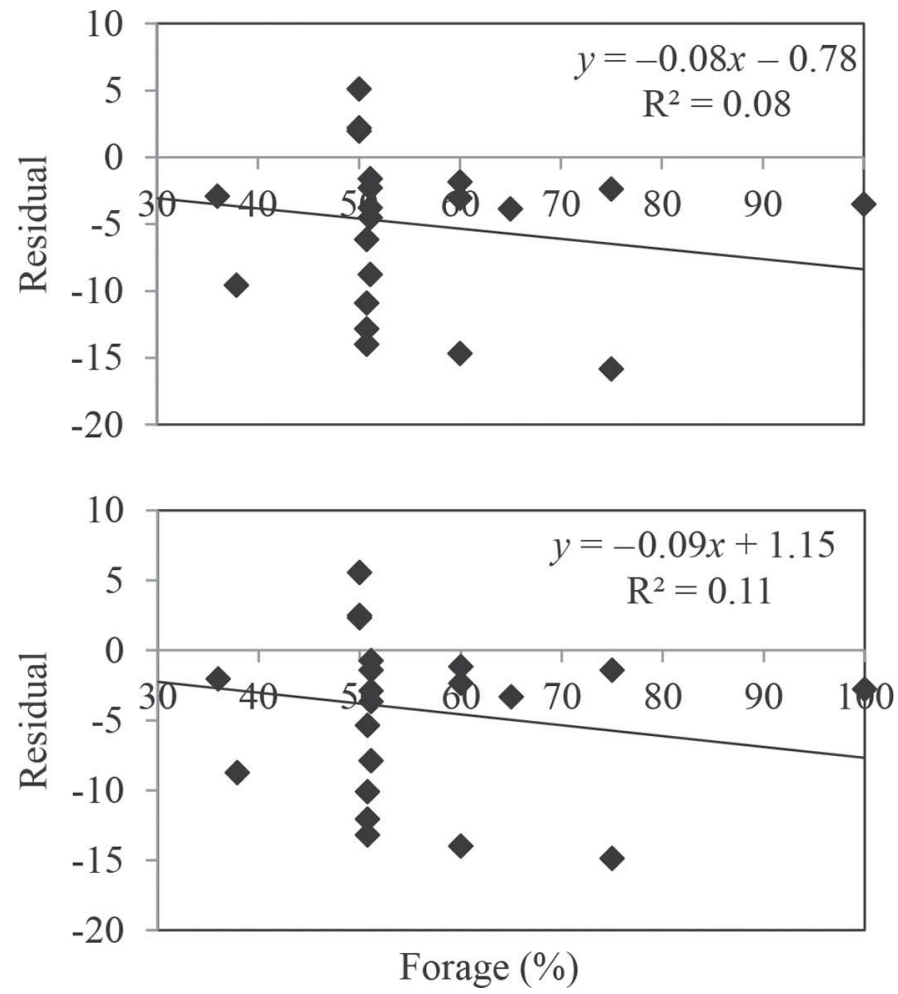

Figure 5. Residual (predicted - observed value) PORBF/HEPBF $(\%)$ versus the forage proportion (\%) in the diet for the DMI-based sheep equations of Vernet et al. (2009), for their above maintenance equation (linear; top), and above plus below maintenance equation (quadratic; bottom), evaluated on the evaluation database, and where $\mathrm{PORBF}=$ portal venous and HEPBF $=$ hepatic venous blood flows.

The sheep equations of Vernet et al. (2009) also tended to overpredict PORBF, HEPBF, and ARTBF, expressed relative to $\mathrm{BW}$, likely illustrating a species difference. Of the 3 sets of extant equations, only those of Vernet et al. (2009) allowed calculation and evaluation of ARTBF and PORBF/HEPBF. Both the Vernet et al. (2009) above maintenance and above + below maintenance linear equations tended to underpredict the mean PORBF/HEPBF. Interestingly, the Vernet et al. (2009) sheep equations also showed a relationship between the PORBF/HEPBF residual and the FP of the diet (Figure 5) with a trend similar to that in the equations derived in the present study (Figure 4), and therefore seem to support the separation of forage and concentrate parameters.

\section{CONCLUSIONS}

Equations developed herein represent advancement over current PORBF, HEPBF, ARTBF, and PORBF/ $\mathrm{HEPBF}$ prediction equations available in the literature for cattle. In the present analysis, a more advanced meta-analysis technique was used, allowing simultane- ous predictions of multiple $\mathrm{BF}$, as well as providing new equations that separate forage DMI from concentrate DMI, resulting in improvements in ARTBF and PORBF/HEPBF predictions. All PORBF and HEPBF equations performed well when tested on an independent database. These equations can be applied within a postabsorptive model of cattle metabolism to predict nutrient fluxes to and from the liver, but should be further evaluated on additional data obtained under a wider range of conditions.

\section{ACKNOWLEDGMENTS}

This research was funded by the Commission of the European Communities (Rednex project FP7KBBE-2007-1), and their financial support is gratefully acknowledged. Funding in part was also provided by the Canada Research Chairs Program (National Science and Engineering Council, Ottawa) and by Dairy Farmers of Canada (Ottawa; Dairy Cluster Project: Balancing dairy rations for protein).

\section{REFERENCES}

Alio, A., C. B. Theurer, O. Lozano, J. T. Huber, R. S. Swingle, A. Delgado-Elorduy, P. Cuneo, D. DeYoung, and K. E. Webb. 2000. Splanchnic nitrogen metabolism by growing beef steers fed diets containing sorghum grain flaked at different densities. J. Anim. Sci. 78:1355-1363.

Barnes, R. J., R. S. Comline, and A. Dobson. 1986. The control of splanchnic blood flow. Pages 41-59 in Proceedings, 6th International Symposium on Ruminant Physiology, Control of Digestion and Metabolism in Ruminants. L. P. Milligan, W. L. Grovum, and A. Dobson, ed. Prentice Hall, Englewood Cliffs, NJ.

Bermingham, E. N., P. Nozière, J. Vernet, H. Lapierre, S. Léger, D. Sauvant, and I. Ortigues-Marty. 2008. The relationship between intake and net portal fluxes of energy metabolites in ruminants: A meta-analysis. Anim. Feed Sci. Technol. 143:27-58.

Bibby, J., and T. Toutenburg. 1977. Prediction and Improved Estimation in Linear Models. John Wiley and Sons, Chichester, UK.

Casse, E. A., H. Rulquin, and G. B. Huntington. 1994. Effect of mesenteric vein infusion of propionate on splanchnic metabolism in primiparous Holstein cows. J. Dairy Sci. 77:3296-3303.

Caton, J. S., C. K. Reynolds, B. J. Bequette, B. Lupoli, P. C. Aikman, and D. J. Humphries. 2001. Effects of abomasal casein or essential amino acid infusions on splanchnic leucine and phenylalanine metabolism in lactating dairy cows. J. Dairy Sci. 84(Suppl. 1):363.

Eisemann, J. H., and G. B. Huntington. 1994. Metabolite flux across portal-drained viscera, liver, and hindquarters of hyperinsulinemic, euglycemic beef steers. J. Anim. Sci. 72:2919-2929.

Eisemann, J. H., and J. A. Nienaber. 1990. Tissue and whole-body oxygen uptake in fed and fasted steers. Br. J. Nutr. 64:399-411.

Ellis, J. L., A. Bannink, J. France, E. Kebreab, and J. Dijkstra. 2010. Evaluation of enteric methane prediction equations for dairy cows used in whole farm models. Glob. Change Biol. 16:3246-3256.

Guerino, F., G. B. Huntington, and R. A. Erdman. 1991. The net portal and hepatic flux of metabolites and oxygen consumption in growing beef steers given postruminal casein. J. Anim. Sci. 69:387-395.

Han, X. T., P. Noziére, D. Rémond, J. Chabrot, and M. Doreau. 2002. Effects of nutrient supply and dietary bulk on O2 uptake and nutrient net fluxes across rumen, mesenteric- and portal-drained viscera in ewes. J. Anim. Sci. 80:1362-1374. 
Hanigan, M. D., C. K. Reynolds, D. J. Humphries, B. Lupoli, and J. D. Sutton. 2004. A model of net amino acid absorption and utilization by the portal-drained viscera of the cow. J. Dairy Sci. $87: 4247-4268$.

Huntington, G. B. 1984. Relationship of portal blood flow to metabolizable energy intake of cattle. Can. J. Anim. Sci. 64:16-17.

Huntington, G. B. 1990. Energy metabolism in the digestive tract and liver of cattle: Influence of physiological state and nutrition. Reprod. Nutr. Dev. 30:35-47.

Huntington, G. B., J. H. Eisemann, and J. M. Whitt. 1990. Portal blood flow in beef steers: Comparison of techniques and relation to hepatic blood flow, cardiac output and oxygen uptake. J. Anim. Sci. 68:1666-1673.

Katz, M. L., and E. N. Bergman. 1969. Simultaneous measurements of hepatic and portal venous blood flow in the sheep and dog. Am. J. Physiol. 216:946-952.

Lapierre, H., D. Pacheco, R. Berthiaume, D. R. Ouellet, C. G. Schwab, P. Dubreuil, G. Holtrop, and G. E. Lobley. 2006. What is the true supply of amino acids for a dairy cow? J. Dairy Sci. 89:E1-E14.

Lautt, W. W. 1996. Intrinsic regulation of hepatic blood flow. Can. J. Physiol. Pharmacol. 74:223-233.

Lautt, W. W. 2009. Hepatic Circulation, Physiology and Pathophysiology. Morgan \& Claypool Life Sciences, San Rafael, CA.

Lescoat, P., D. Sauvant, and A. Danfaer. 1996. Quantitative aspects of blood and amino acid flows in cattle. Reprod. Nutr. Dev. 36:137174 .

Lin, L. I. K. 1989. A concordance correlation coefficient to evaluate reproducibility. Biometrics 45:255-268.

Littell, R. C., G. A. Milliken, W. W. Stroup, R. D. Wolfinger, and O. Schabenberger. 2006. SAS System for Mixed Models, Second Edition. SAS Inst. Inc., Cary, NC.

Lobley, G. E., G. D. Milano, and J. G. van der Walt. 2000. The Liver: Integration of Nitrogen Metabolism. Pages 149-168 in Ruminant Physiology. Digestion, Metabolism, Growth and Reproduction. P. B. Cronje, ed. CABI Publishing, Wallingford, UK.

Maltby, S. A., C. K. Reynolds, M. A. Lomax, and D. E. Beever. 2005. Splanchnic metabolism of nutrients and hormones in steers fed alfalfa under conditions of increased absorption of ammonia and L-arginine supply across the portal-drained viscera. J. Anim. Sci. $83: 1088-1096$

Moser, E. B. 2004. Repeated measures modeling with PROC MIXED. Paper 188-29 in Proc. Twenty-Ninth Annu. SAS Users Group Int. Conf. SAS Inst. Inc., Cary, NC.

Reynolds, C. K., P. C. Aikman, B. Lupoli, D. J. Humphries, and D. E. Beever. 2003a. Splanchnic metabolism of dairy cows during the transition from late gestation through early lactation. J. Dairy Sci. 86:1201-1217.

Reynolds, C. K., B. J. Bequette, J. S. Caton, D. J. Humphries, P. C. Aikman, B. Lupoli, and J. D. Sutton. 2001. Effects of intake and lactation on absorption and metabolism of leucine and phenylalanine by splanchnic tissues of dairy cows. J. Dairy Sci. 84(Suppl. 1):362.

Reynolds, C. K., L. A. Crompton, K. Firth, D. E. Beever, J. Sutton, M. Lomax, D. Wray-Cahen, J. Metcalf, E. Chettle, B. Bequette, C. Backwell, G. E. Lobley, and J. MacRae. 1995a. Splanchnic and milk protein responses to mesenteric vein infusion of 3 mixtures of amino acids in lactating dairy cows. J. Anim. Sci. 73(Suppl. 1): 274 .

Reynolds, C. K., D. L. Harmon, R. L. Prior, D. P. Casper, and C. T. Milton. 1995b. Splanchnic metabolism of amino acids in beef steers fed diets differing in CP content at two ME intakes. J. Anim. Sci. 73(Suppl. 1):270.

Reynolds, C. K., D. L. Harmon, R. L. Prior, and H. F. Tyrrell. 1994a. Effects of mesenteric vein L-alanine infusion on liver metabolism of organic acids by beef heifers fed diets differing in forage-toconcentrate ratio. J. Anim. Sci. 72:3196-3206.

Reynolds, C. K., D. J. Humphries, S. B. Cammell, J. Benson, J. D. Sutton, and D. E. Beever. 1998. Effects of abomasal wheat starch infusion on splanchnic metabolism and energy balance of lactating dairy cows. Pages 39-42 in Energy Metabolism of Farm Animals, Proceedings of the 14th Symposium on Energy Metabolism. K. J. McCracken, E. F. Unsworth, and A. R. G. Wylie, ed. CAB International

Reynolds, C. K., G. B. Huntington, and H. F. Tyrrell. 1994b. Effects of feeding maize grain harvested at 2 stages of maturity on net nutrient metabolism by splanchnic tissues of lactating dairy cows. Anim. Prod. 58:433.

Reynolds, C. K., H. Lapierre, H. F. Tyrrell, T. H. Elsasser, R. C. Staples, P. Gaudreau, and P. Brazeau. 1992a. Effects of growth hormone-releasing factor and feed intake on energy metabolism in growing beef steers: Net nutrient metabolism by portal-drained viscera and liver. J. Anim. Sci. 70:752-763.

Reynolds, C. K., B. Lupoli, P. C. Aikman, D. J. Humphries, L. A. Crompton, J. D. Sutton, J. France, D. E. Beever, and J. C. MacRae. 1999. Effects of abomasal casein or essential amino acid infusions on splanchnic metabolism in lactating dairy cows. J. Anim. Sci. 77(Suppl. 1):266

Reynolds, C. K., J. A. Benson, P. C. Aikman, B. Lupoli, M. D. Hanigan, D. E. Beever, and J. C. MacRae. 2003b. Effects of diet forage:concentrate ratio on splanchnic nutrient metabolism in lactating dairy cows. J. Dairy Sci. 86(Suppl. 1):219.

Reynolds, C. K., S. A. Maltby, and D. L. Harmon. 1993. Effects of mesenteric vein L-glycine infusion on liver metabolism in beef steers. FASEB J. 7:A525.

Reynolds, C. K., and H. F. Tyrrell. 1991. Effects of mesenteric vein L-alanine infusion on liver metabolism in beef heifers fed on diets differing in forage:concentrate ratio. Br. J. Nutr. 66:437-450.

Reynolds, C. K., H. F. Tyrrell, and L. E. Armentano. 1992b. Effects of mesenteric vein $n$ butyrate infusion on liver metabolism of beef steers. J. Anim. Sci. 70:2250-2261.

Reynolds, C. K., H. F. Tyrrell, and P. J. Reynolds. 1991. Effects of diet forage-to-concentrate ratio and intake on energy metabolism in growing beef heifers: Whole body energy and nitrogen balance and visceral heat production. J. Nutr. 121:994-1003.

Røjen, B. A., P. K. Theil, and N. B. Kristensen. 2011. Effects of nitrogen supply on inter-organ fluxes of urea-N and renal urea-N kinetics in lactating Holstein cows. J. Dairy Sci. 94:2532-2544.

Sauvant, D., P. Schmidely, J. J. Daudin, and N. R. St-Pierre. 2008. Meta-analysis of experimental data in animal nutrition. Animal 2:1203-1214.

St-Pierre, N. R. 2001. Invited review: Integrating quantitative findings from multiple studies using mixed model methodology. J. Dairy Sci. 84:741-755.

Strathe, A. B., A. Danfaer, A. Chwalibog, H. Sorensen, and E. Kebreab. 2010. A multivariate nonlinear mixed effects method for analyzing energy partitioning in growing pigs. J. Anim. Sci. 88:2361-2372

Strathe, A. B., A. Danfær, H. Sørensen, and E. Kebreab. 2010b. A multilevel nonlinear mixed-effects approach to model growth in pigs. J. Anim. Sci. 88:638-649.

Vernet, J., H. Lapierre, P. Noziére, S. Léger, D. Sauvant, and I. Ortigues-Marty. 2005. Prediction of blood nutrient supply to tissues of economical interest in ruminants: A first step with the prediction of portal blood flow. Pages 163-173 in Proceedings of the First Open International Conference on Modeling and Simulation, OICMS. D. R. C. Hill, V. Barra, and M. K. Traore, ed. Blaise Pascal University, Clermont-Ferrand, France.

Vernet, J., P. Nozière, S. Léger, D. Sauvant, and I. Ortigues-Marty. 2009. Responses of hepatic blood flows to changes in intake in sheep: A meta-analysis. Animal 3:1387-1400.

Whitt, J., G. Huntington, E. Zetina, E. Casse, K. Taniguchi, and W. Potts. 1996. Plasma flow and net nutrient flux across gut and liver of cattle fed twice daily. J. Anim. Sci. 74:2450-2461.

Wieghart, M., R. Slepetis, J. M. Elliot, and D. F. Smith. 1986. Glucose absorption and hepatic gluconeogenesis in dairy cows fed diets varying in forage content. J. Nutr. 116:839-850. 